\title{
Lässtrategier i teknikämnen ger elever redskap för att utveckla yrkeskunskap
}

\author{
Malin Viklund
}

Luleå Gymnasieskola Teknikprogrammet

\begin{abstract}
Läsning av faktatexter i yrkesspecifika ämnen utgör en utmaning för eleverna. Jag har genom att inkludera undervisning om lässtrategier parallellt med ämnesundervisningen inom husbyggnad på teknikprogrammet utvecklat ett arbetssätt för att stimulera elevernas läsning och förmåga att ta till sig, lära sig och förstå det ämnesspecifika innehållet. Resultatet visade att det blev skillnad. När jag tidigare lät elever arbeta traditionellt med instuderingsfrågor gav de svar som innehöll den kunskap jag valt ut åt dem. När jag nu istället lät elever arbeta med lässtrategier parallellt med ämnesundervisning visade de större förmåga att använda relevanta begrepp, analysera och beskriva kopplingar i ämnet samt dra slutsatser av det de lärt sig.
\end{abstract}

Läsning är en grundläggande förmåga som eleverna behöver för att kunna tillgodogöra sig kunskaper av undervisningen. I en kursutvärdering för några år sedan fick jag en kommentar av en elev som beskrev att facklitteraturen vi använde i undervisningen var svår att läsa och förstå. Den enkla kommentaren gjorde att jag började fundera på vilka orsaker som låg bakom elevens upplevelse. Min första reflektion gjorde jag till själva undervisningsämnet. Jag undervisar i byggtekniska ämnen på det högskoleförberedande teknikprogrammet. Där är många av de ämnesspecifika begrepp som används i undervisningen nya för de flesta av eleverna. Min andra reflektion kopplades till elevens förmåga att läsa faktatexter. Kan det finnas något i elevens förmåga att läsa som gör det extra svårt och vad kan jag som lärare i så fall göra för att hjälpa eleverna?

Med den frågan ska jag i artikeln beskriva några reflektioner som jag gjorde i samband med att jag genomförde och dokumenterade ett praktiknära forskningsprojekt [1] om att inkludera lässtrategier i min egen undervisning i yrkesämnen. Jag vill synliggöra behovet av strategisk planering för att inkludera läsundervisning i ämnesundervisningen och visa hur det kan påverka eleverna som aktiva läsare.

Innan jag själv fördjupade mig om läsningens betydelse hade jag inte reflekterat över vem som äger texten. När jag tidigare förberedde presentationsmaterial och sammanställde instuderingsfrågor till ett avsnitt var det jag och inte eleverna som valde ut vad som var viktigt att lära sig. Jag valde omedvetet att förenkla det yrkesspecifika ämnet vilket gjorde att undervisningsnivån sjönk och elevernas förmåga att uttrycka sig stannade i ett vardagsspråk. Arbetet med att inkludera lässtrategier i ämnesundervisningen har gett mig en förståelse för att vårt eget förhållningssätt till lärande påverkar elevernas förmåga att lära sig. Mina högt ställda förväntningar på eleverna ställde krav på att även jag behövde anpassa undervisningen efter givna förutsättningar. Genom att arbeta med lässtrategier försåg jag eleverna med fler redskap för läsningen så att de själva kan vara med och påverka sitt lärande.

\section{Läsförståelse kan stödjas genom att undervisa om lässtrategier}

Ämnesundervisningens innehåll styrs av det centrala innehållet i ämnet och de förmågor eleverna ska uppvisa enligt kunskapskraven. Under min lärarutbildning pratade vi främst ämnesdidaktik och reflekterade inte särskilt mycket över andra förmågor som eleverna behöver för att kunna ta till sig 
ämneskunskaperna. Läsning och läsförståelse är ett sådant område som jag tidigare naivt ansåg inte berörde min undervisning; jag tänkte att det var andra lärares uppgift att lära eleverna detta. Jag har nu förstått att läsning och den betydelse det har för elevernas lärande borde vara alla lärares ansvar att ta sig an i undervisningen.

Läsförståelse är enligt Roe [2] och Westlund [3] något som bör undervisas om genom hela skolperioden. Studier har visat att sättet att undervisa på har betydelse för vilken effekt det får för läsförståelsen. Undervisningen ska därför alltid anpassas efter vilket innehåll vi vill förmedla och vilken undervisningsgrupp vi möter i klassrummet.

De lässtrategier eleverna använder kan enligt Roe [2] delas in i tre olika grupper:

- Memoreringsstrategier: Enkla strategier som att lyssna, anteckna, stryka under och läsa högt används för att fokusera på fakta, detaljer och till viss del för utantillinlärning.

- Fördjupningsstrategier: Utvecklade strategier för att sätta informationen i ett större sammanhang. Eleven utgår från sina förkunskaper, använder texternas uppbyggnad och struktur, gör kopplingar samt skriver sammanfattningar för att få en fördjupad förståelse av det lästa.

- Kontrollstrategier: Innebär att eleven har en egen medvetenhet om olika lässtrategier och vilken betydelse de har för inlärningen.

Undervisning som inkluderar lässtrategier kan således hjälpa eleverna att göra medvetna val och påverka elevernas läsning positivt. Eleverna behöver förstå syftet med läsningen och kunna identifiera viktiga nyckelord och avsnitt, för att sedan själva kunna avgöra om deras förståelse av texten är tillräcklig. Skickliga läsare känner även till att lässtrategier har betydelse för läsförståelsen. I undervisningen kan jag som lärare hjälpa eleverna hitta motivation för att läsa genom att inkludera kunskap om lässtrategier i min undervisning.

\section{Lässtrategier som didaktiskt komplement till undervisning om praktisk husbyggnadsteknik}

Insikten om mitt ansvar för elevernas läsande har inneburit att jag medvetet har lagt in strategier för läsning som ett komplement till ämneskunskaperna för att hjälpa eleverna att arbeta med och förstå textmaterialet på olika sätt. Den språkliga stöttningen i de byggtekniska ämnena omfattade flera olika delar, vilket jag kommer att redogöra för här.

I början av ett arbetsområde om praktisk husbyggnadsteknik ställde jag följande förkunskapsfråga till eleverna: Vad känner du till om byggnader idag? Jag delade sedan ut en bild av en byggnad i genomskärning och uppmanade eleverna att fylla på med text i bilden. De började med att göra detta enskilt, och efter en stund bad jag eleverna att diskutera och komplettera texten i bilden tillsammans med en klasskamrat. Därefter resonerade vi om erfarenheterna tillsammans. I den gemensamma diskussionen kunde jag koppla elevernas reflektioner till vad hela arbetsområdet om praktisk husbyggnadsteknik skulle handla om. Jag kunde både bekräfta elevernas tidigare erfarenheter och bygga vidare från där de var kunskapsmässigt.

Vid det första tillfället introducerade jag också arbete med egna ordlistor. I boken Praktisk husbyggnadsteknik [4] som jag använder i min undervisning finns en byggnadsteknisk ordlista med ca 150 begrepp. Ordlistan tar upp ett urval av viktiga begrepp som elever behöver för att kunna uttrycka sin byggnadstekniska kunskap. Direkt efter förkunskapsövningen bad jag eleverna gå igenom hela ordlistan och markera alla begrepp som de redan kunde förklara samt begrepp de hört talas om men inte riktigt kunde förklara innebörden av. Sedan gick jag återkommande tillbaka till ordlistan och bad eleverna markera nya begrepp, såsom cellplast när vi hade haft lektion om byggnadsmaterial och centrumavstånd när vi arbetat med regelstommens konstruktion. I slutet av arbetsområdet visade det sig att eleverna ansåg att drygt hälften av orden var väsentliga för det 
kunskapsinnehåll vi fokuserat på. På detta sätt fick eleverna själva skapa en lista inför examinationen med de byggtekniska begrepp som ämnesområdet innehöll istället för att jag sammanställt motsvarande begrepp i instuderingsfrågor.

Vid det andra tillfället introducerade jag tanken om lässtrategier för eleverna. För att eleverna skulle förstå arbetssättet förklarade jag för dem att lässtrategier handlar om hur de som läsare tar sig an en ny text. Jag berättade för eleverna att jag i arbetsområdet skulle introducera flera olika lässtrategiska verktyg som eleven kan använda sig av i min eller andra kurser. Med inspiration från Gears [5] och Ingemarssons [6] tankar om undervisning om kritisk och reflekterande läsning tryckte jag upp ett bokmärke (Figur 1) till eleverna för att de skulle ha lässtrategierna lättillgängliga. Det första kring lässtrategier jag återkopplade till eleverna om, var deras egna förkunskaper. Förkunskaperna är viktiga att synliggöra för att eleverna ska kunna bygga vidare på sina kunskaper.

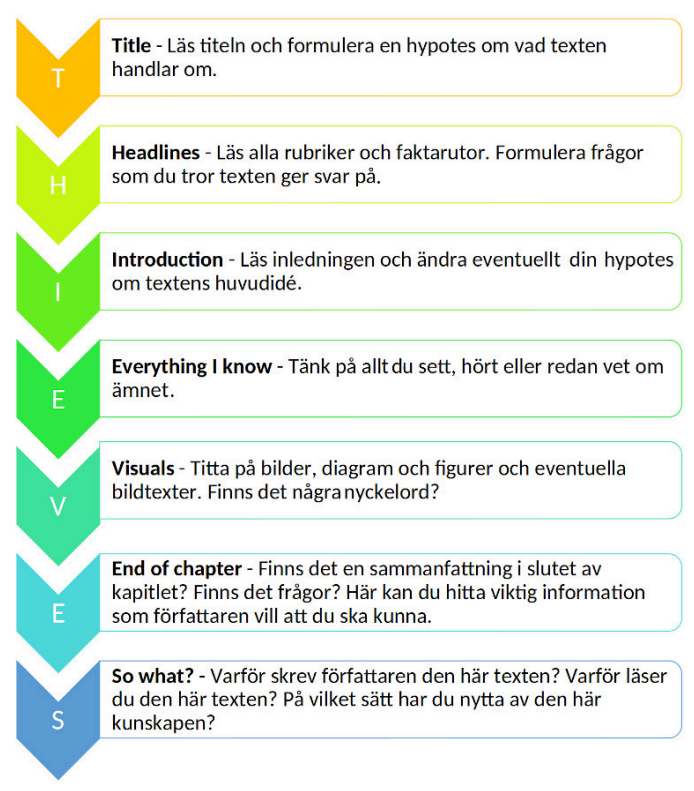

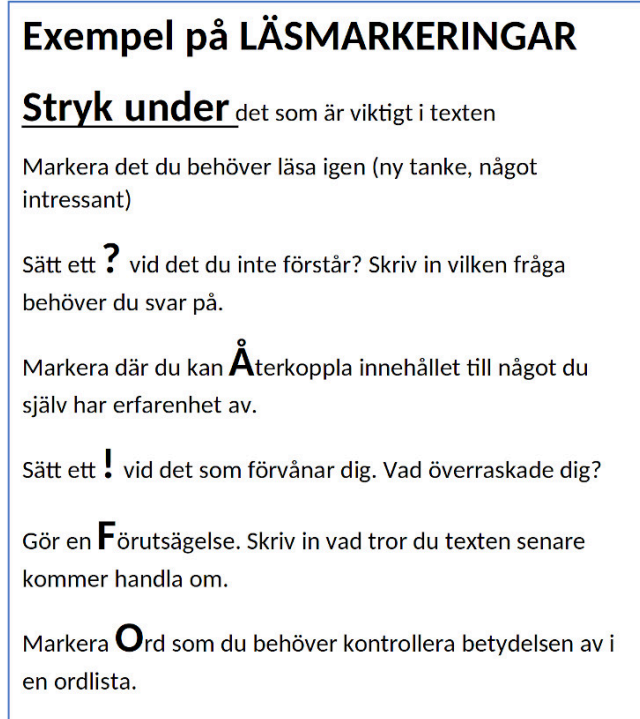

Figur 1. Bokmärke till eleverna med inspiration av Gear [5] och Ingemarsson [6].

Därefter tillämpade vi läsmarkeringar, genom att exempelvis stryka under det som är viktigt och att markera det som är oklart i texten. Ett inledande avsnitt i boken läste jag högt för eleverna. De uppmanades att göra läsmarkeringar under tiden som de lyssnade. Efter högläsningen gick vi tillsammans igenom det eleverna markerat och diskuterade svåra begrepp, innebörd och sammanhang i texten. Många gånger var det inte de byggnadstekniska begreppen som var svåra utan de mellanliggande orden som gör faktatextens innehåll förståeligt.

Övningen med högläsning hade för avsikt att synliggöra för eleverna att de själva kan göra läsmarkeringar i material de läst eller skrivit. Syftet med läsmarkeringar av olika slag är att eleverna ska synliggöra för sig själva vad som är viktigt och vad de inte förstår i textmaterialet. Läsmarkeringar utgör också grund för att eleverna ska kunna skriva sammanfattningar av det de läst eller fått höra, vilket annars kan vara väldigt krävande för eleverna. I samband med uppgiften förklarade jag för eleverna att läsmarkeringar kan synliggöra vilka avsnitt de har förtrogenhet med och vilka de behöver fokusera mer på.

Det systematiska angreppssättet THIEVES, som också fanns med på bokmärket (se illustration till vänster i Figur 1), använde vi för att kunna avgöra vad som är viktigt i en text. Gear [5] beskriver 
strategin som en påminnelse för eleverna att se vilken betydelse textens struktur har för läsningen. Tillsammans med eleverna la jag relativt mycket tid på THIEVES som språklig stöttning. Genom att återkommande inleda med att tillsammans analysera och diskutera rubriker och underrubriker i ett nytt textavsnitt kunde vi aktivera elevernas förkunskaper. Eleverna kunde skapa sig en initial föreställning om vad texten troligtvis skulle handla om bara genom att studera rubriken. Genom systematiken i lässtrategierna kunde vi sedan bygga på elevernas tidigare kunskaper.

Bilder kan vara mycket bra komplement för att eleverna ska förstå en faktabaserad text. I byggteknisk litteratur ingår figurer och illustrationer som en naturlig del för att förstå hur olika byggnadskomponenter sammanfogas till en helhet. Vid ett tillfälle studerade vi därför endast bildmaterialet som fanns i en text för att genom bilderna förstå byggtekniska komponenter och hur olika komponenter är beroende av varandra. För att kunna bearbeta textens innehåll baserat enbart på bilderna förberedde jag och ritade av de bilder ur faktatexterna som eleverna behövde. Anledningen till att eleverna i förväg fick mina bilder var att fokus skulle ligga på de byggnadstekniska faktorerna och inte på rittekniken. Kunskapen om att rita korrekta byggtekniska detaljer kommer med kunskapen om vilka funktioner som finns med i en byggteknisk konstruktion. Under genomgången kunde eleverna själva skriva in olika byggtekniska begrepp och gör egna minnesanteckningar utifrån det jag tog upp. När eleverna sedan läste faktatexterna kunde de själva se vilka delar av texterna som vi fokuserat på under arbetet med bilderna.

Att själv ställa frågor till texten är ytterligare en viktig lässtrategi som vi arbetade med. Genom hela arbetsområdet hade jag därför en återkommande övergripande fråga som jag ville att eleverna skulle fokusera på: Varför finns det inte bara en konstruktionslösning när man ska bygga hus? Syftet med frågan var att synliggöra för eleverna var de skulle ha fokus när de arbetade med texterna. Mina erfarenheter säger att eleverna annars lätt hamnar i frågor som bara är fokuserade på fakta och detaljer istället för att få överblick över och förståelse för arbetsområdet som helhet. Inför examinationen bad jag även eleverna förbereda provfrågor på texten. Genom denna uppgift kunde vi diskutera hur faktakunskaper bygger upp förståelsen för ämnesområdet.

\section{Undervisning med lässtrategier gav mer elevinteraktioner på lektionerna}

Det var spännande att följa vad som hände på lektionerna när ämnesundervisningen kompletterades med kunskap om lässtrategier. I tidigare genomförda lektioner där jag föreläste och eleverna efteråt arbetade med instuderingsfrågor uppkom inga eller få spontana diskussioner. Eleverna arbetade individuellt med större eller mindre motivation. Jag upplevde att elevernas inre motivation och engagemang påverkades när jag förändrade min undervisning. Eleverna ställde fler frågor, diskuterade med varandra och agerade i klassrummet på ett helt annat sätt än tidigare.

Mitt förhållningssätt gentemot läsförståelse och användningen av lässtrategier i undervisningen ger, enligt mig, eleverna fler möjligheter att motiveras och öka sin lust att läsa faktatexter. Ryan och Deci [7] beskriver att elevens inre motivation stärks av deras förmåga att själva styra vad de behöver göra för att nå sina mål och tro på sin egen förmåga att lyckas med en uppgift. Elever med låg självkänsla kan genom mitt förhållningssätt med yttre motivation, såsom att aktivt vara nyfiken på elevernas egna tankar och funderingar, stimuleras att tro på sig själva och lyckas med uppgifter. Elever kan med rätt stimulans själva styra över sitt eget lärande.

De första tydliga elevinteraktionerna syntes redan i förkunskapsuppgiften, vilket ledde till en bra dialog i klassrummet. Som jag nämnt tidigare fick alla elever förbereda sig enskilt (se elevexempel i Figur 2) inför en diskussion i par. Under den efterföljande diskussionen med en klasskamrat uppstod samtal kring elevernas erfarenheter om olika byggnadsmaterial, byggnadsdelar och funktioner som de olika byggdelarna ska uppfylla. Någon elev berättade stolt när hen fått vara med morfar att bygga. Sådana erfarenheter kan jag sedan använda i min fortsatta undervisning genom att ställa följdfrågor som får eleverna att reflektera ytterligare. 


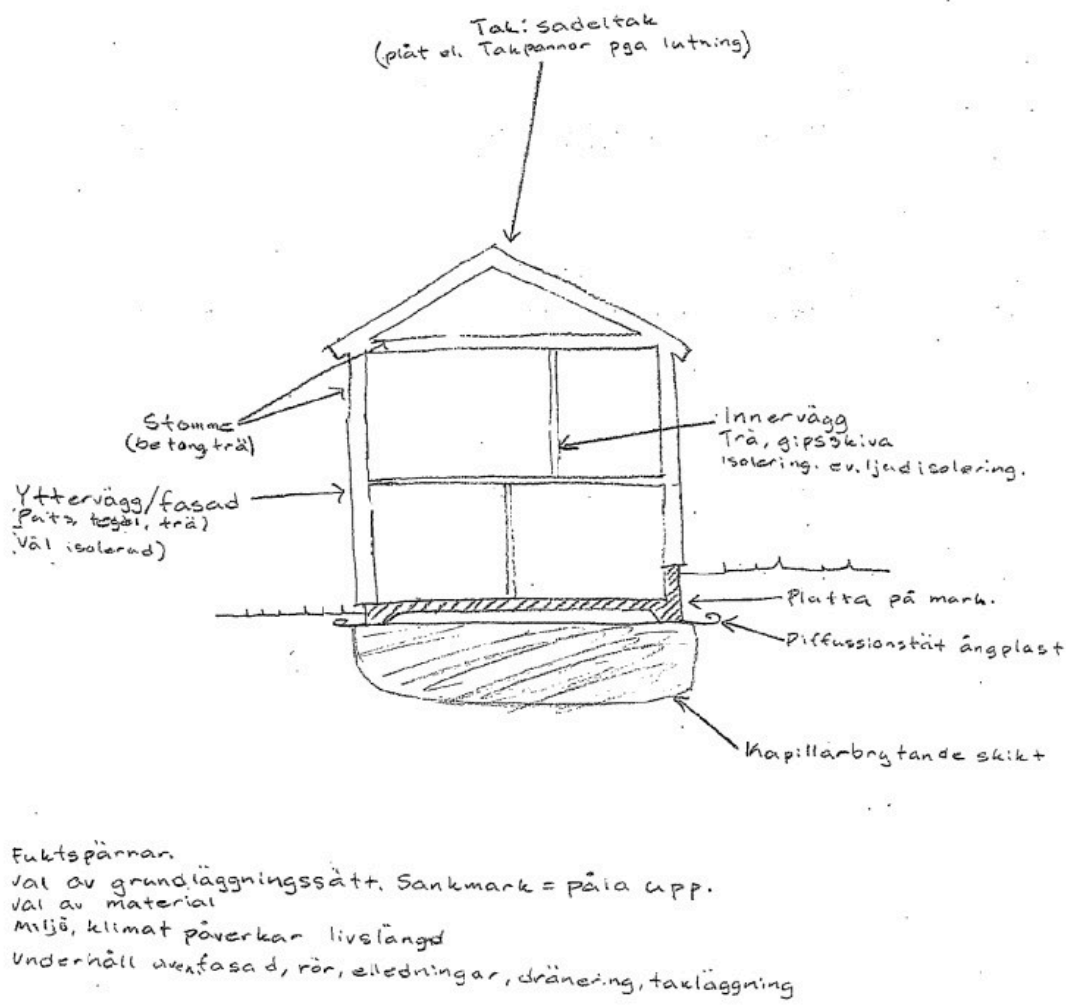

Figur 2. En elev uppvisar utförliga förkunskaper.

Ordlistan i Praktisk husbyggnadsteknik [4] användes frekvent av eleverna. Under de första lektionerna bad jag aktivt eleverna att ta fram ordlistan och markera de begrepp som kommit till efter dagens genomgång. Senare använde eleverna på eget bevåg ordlistan som grund för gemensamma diskussioner. De började ofta med en "vad är?"-fråga för att sedan diskutera i vilket sammanhang begreppet används. I den gemensamma diskussionen stärktes elevernas kunskap om byggnadstekniska begrepp och deras förståelse för vilka faktorer som påverkar byggnadens utformning och konstruktion. Återigen gavs jag möjlighet att återknyta till elevernas egna diskussioner.

En annan spännande iakttagelse som jag vill dela med mig av rör tempot i klassrummet. När jag i mitt ursprungliga upplägg använde mig av en förberedd powerpoint var tempot högt och eleverna fick liten tid att reflektera över det som sas i klassrummet. Eleverna antecknade inte i någon högre grad eftersom de visste att jag gett dem åhörarkopior av min presentation. När jag i det nya upplägget istället exempelvis använde figurer ur läroboken och diskuterade innehållet i bilden gick tempot ner och eleverna hann göra egna anteckningar och reflektera över vad de förstod och inte förstod. Eleverna fick då möjlighet att stanna upp och ställa frågor om sådant de behöver hjälp att förstå. Eleverna ägde även sitt eget material. Figurer jag ritar på tavlan kan ibland tyckas otydliga, men som en elev uttryckte sig: Om man ser tavlan nu kan det kännas rörigt men eftersom vi tog det steg för steg så känns det bra. Jag har skapat mitt eget material.

Lässtrategin att ställa frågor till texten gav eleverna möjlighet att resonera om frågans betydelse. Två typfrågor som eleverna formulerade kunde se ut så här:

- Vad är olyckslast?

- Hur påverkas byggnaden av vind?

Vid en gemensam diskussion kunde jag återkoppla till eleverna att den första frågan eleven 
formulerade är faktainriktad, den kräver att eleven lärt sig vad olyckslast är. Den andra frågan ger eleverna mer möjligheter att reflektera. Eleven kan beskriva att vindlasterna beror på var i landet vi bygger eller att de är beroende på hur terrängen i landskapet ser ut. Den utvecklade frågan aktiverar elevens kritiska och reflekterande läsning som Gear [5] påtalar.

Elevinteraktionerna i klassrummet berodde till stor del på hur jag som lärare systematiskt använde lässtrategierna för att inspirera och motivera eleverna. Genom att uppmuntra eleverna att studera bilder, sammanfatta det de läst eller ställa frågor till texten skapades tydligare elevinteraktioner i jämförelse med när jag tidigare använde mig av instuderingsfrågor.

Mitt nuvarande förhållningssätt innebär att jag tror på att eleverna själva kan söka vad som är viktigt att förstå i en faktatext, bara de får rätt verktyg för att klara av utmaningen. Den här tron på elevernas egen förmåga speglade även av sig i elevernas skriftliga examination. De elever som arbetade med instuderingsfrågor gav svar som innehöll den kunskap jag valt ut åt dem medan de elever som parallellt arbetat med lässtrategier visade större förmåga att använda relevanta begrepp, analysera och beskriva kopplingar i ämnet samt dra slutsatser av det de lärt sig. Eleverna kunde aktivt ta del av en faktatext och öka förståelsen av det specifika ämnet.

\section{BYGGA kunskap - vad innebär det?}

Jag gav min magisteruppsats titeln BYGGA kunskap [1] för jag tror att undervisning som inkluderar lässtrategier kan bygga elevernas kunskap inte bara i yrkesämnen utan i alla ämnen. Vi lärare ska kontinuerligt i vår profession reflektera över vad i vår undervisning som fungerar och vad som kan utvecklas ytterligare. Jag tror att vi behöver lära oss se de små förändringarna som kan göra stor skillnad för elevernas möjlighet att nå måluppfyllelse. Genom att genomföra strategiska utvecklingsinsatser likt den om att inkludera lässtrategier i undervisningen har jag fått syn på hur eleverna tänker i mina ämnen och hur jag med enkla justeringar kan förändra lärandesituationen och analysera vilka effekter det haft på elevernas lärande.

Bilden med byggklossar (Figur 3) symboliserar min tolkning av resultatet, att komplettera elevernas ämneskunskaper med kunskaper om hur man kan ta sig an en faktabaserad text. Den första bilden får symbolisera elevernas kunskaper efter ämnesundervisning. Byggklossarna i den mittersta bilden symboliserar verktygslådan med lässtrategier som ämnesundervisningen kompletterades med och den sista bilden symboliserar skillnaden i den utvecklade kunskap eleverna kunde presentera i slutet av arbetsområdet. Eleverna hade BYGGT en mer utvecklad och specifik kunskap inom ämnesområdet och utvecklat sin förmåga att analysera varför det inte bara finns en lösning inom husbyggnadsteknik. Avslutningsvis vill jag skicka med er läsare att fundera på vilka fler små förändringar vi lärare kan inkludera som skapar bättre förutsättningar för våra elever att nå sina kunskapsmål.
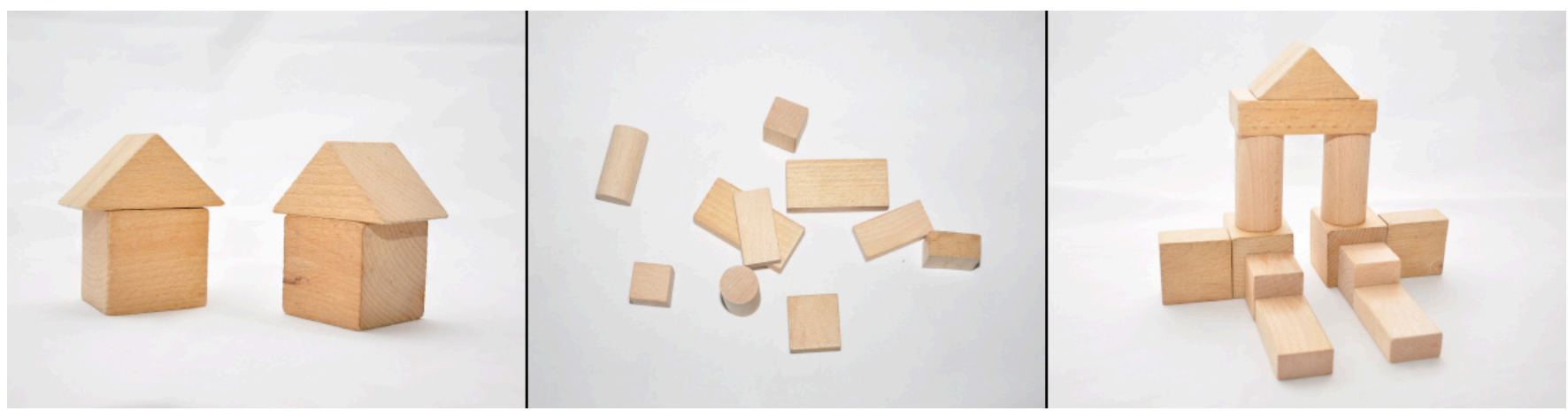

Figur 3. Undervisning som inkluderar lässtrategier kan ha stor betydelse i yrkesämnen. 


\section{Författare}

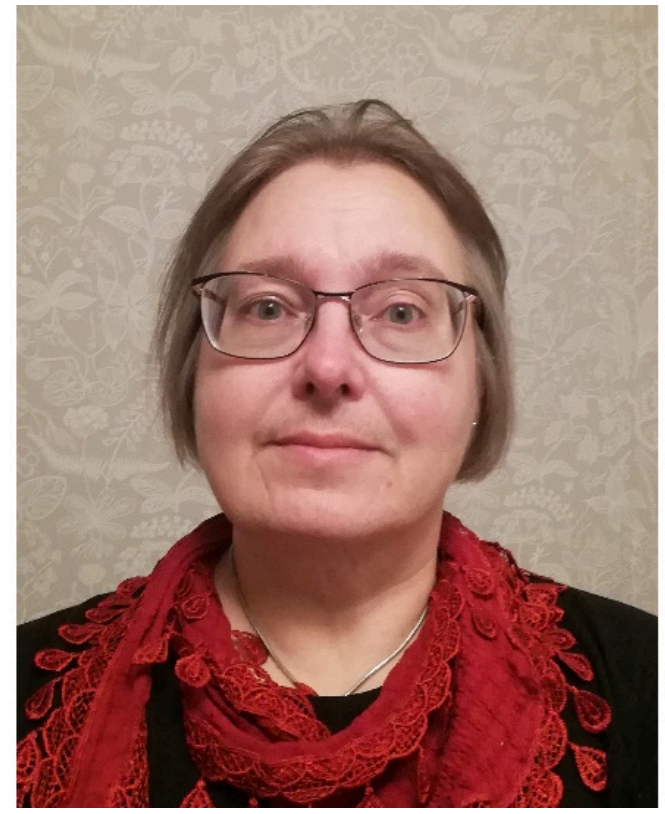

Figur 4. Malin Viklund

Malin Viklund är gymnasielärare på Teknikprogrammet vid Luleå Gymnasieskola och har en filosofie magisterexamen i Utbildningsvetenskap (Figur 4). Hon undervisar på inriktningen Samhällsbyggande och miljö. Malin är även förstelärare för att utveckla teknikämnena på programmet.

\section{Referenser}

1. Viklund M. BYGGA kunskap - ett praktiknära forskningsprojekt om hur lässtrategier kan inkluderas i undervisning i yrkesämnen på gymnasiet och vilka förutsättningar det skapar för eleverna. (Magisteruppsats). Luleå tekniska universitet; 2019.

2. Roe A. Läsdidaktik - efter den första läsinlärningen. Malmö: Gleerup; 2015.

3. Westlund B. Att undervisa i läsförståelse - lässtrategier och studieteknik. Stockholm: Natur \& Kultur; 2009.

4. Sandin K. Praktisk husbyggnadsteknik. Stockholm: Studentlitteratur; 2019.

5. Gear A. Att läsa faktatexter - undervisning i kritisk och reflekterande läsning. Stockholm: Natur \& Kultur; 2015.

6. Ingemarsson M. Djupläsning och lässtrategier. Acta didactica Norge. 2018;12(2).

7. Ryan R, Deci E. Intrinsic and extrinsic motivations: Classic definitions and new directions. Contemporary educational psychology. 2000;25(1):54-67. 